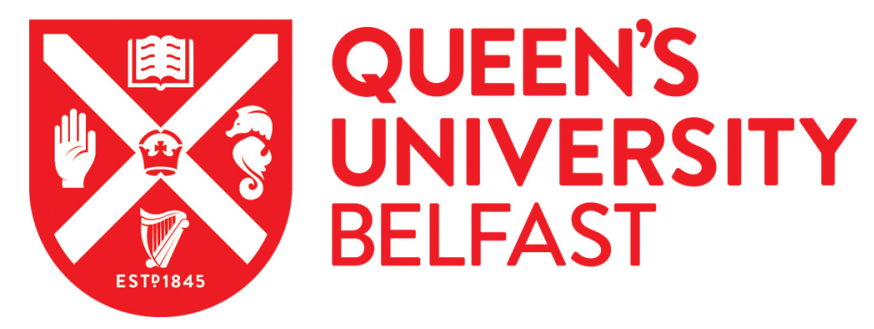

\title{
A Public Access Defibrillation trial in urban and rural communities in Northern Ireland: Developing the roster model
}

Cairns, K., Marshall, A., \& Kee, F. (2005). A Public Access Defibrillation trial in urban and rural communities in Northern Ireland: Developing the roster model. 497-502. Paper presented at 18th IEEE International Symposium on Computer-Based Medical Systems (IEEE CBMS), Dublin, Ireland.

Queen's University Belfast - Research Portal:

Link to publication record in Queen's University Belfast Research Portal

\section{General rights}

Copyright for the publications made accessible via the Queen's University Belfast Research Portal is retained by the author(s) and / or other copyright owners and it is a condition of accessing these publications that users recognise and abide by the legal requirements associated with these rights.

Take down policy

The Research Portal is Queen's institutional repository that provides access to Queen's research output. Every effort has been made to ensure that content in the Research Portal does not infringe any person's rights, or applicable UK laws. If you discover content in the Research Portal that you believe breaches copyright or violates any law, please contact openaccess@qub.ac.uk. 


\title{
A Public Access Defibrillation Trial in Urban and Rural Communities in Northern Ireland: Developing the Roster Model
}

\author{
Karen J. Cairns, Adele H. Marshall, Frank Kee \\ Queen's University of Belfast, Northern Ireland, UK. \\ $\{$ k.cairns,a.h.marshall, f.kee\}@qub.ac.uk
}

\begin{abstract}
This paper introduces a special computer-based roster scheme developed to allocate and manage volunteers working as part of a Public Access Defibrillation trial. The roster scheme, developed for the urban region, is rooted on population statistics and demographics for that area and utilizes geographical mapping software and spatial modelling techniques to subdivide the geographical location into appropriate paging zones. The central location for zones was constrained to be within a reasonable travelling time for each volunteer. By estimating Sudden Cardiac Arrest occurrences using a Poisson process, the model, together with road network information, selects a roster which minimizes volunteer response time.
\end{abstract}

\section{Introduction}

Coronary heart disease (CHD) is the most common cause of death in the Western World $[1,2]$. Such deaths are often due to Sudden Cardiac Arrest (SCA) [2-4], which can be confirmed by the absence of a detectable pulse, unresponsiveness and lack of breathing [5]. Survival rates from out-of-hospital SCA are typically low (approximately 5\%) [6-9]. It is therefore a major public health challenge to reduce mortality from out-of-hospital SCA.

When out-of-hospital SCA is caused by ventricular fibrillation (VF), defibrillation is an effective treatment [10]. However, the effectiveness of the procedure is highly timedependent. From the moment of collapse, the likelihood of survival decreases rapidly with each minute that elapses without initiation of life-saving procedures. After a 10 minute delay in defibrillation, more than $90 \%$ of victims do not survive or survive with severe neurological deficiency [11].

Public Access Defibrillation (PAD) schemes aim to reduce the time interval from collapse to defibrillation through equipping lay volunteers with Automatic External Defibrillators (AEDs). These devices are capable of automatically detecting and treating VF, and enable lay volunteers to defibrillate safely, with just a few hours of training. Evidence of the potential effectiveness of PAD exists from previous observational trials [12-16]. However the success in any one particular community will ultimately depend on the extent to which the scheme's implementation has taken into account important factors, such as the type of emergency medical services (EMS) system in that area, the demographic profile of the community and local geography.

In Northern Ireland (NI), an observational trial is underway, that aims to examine the effectiveness and cost-effectiveness of PAD in both urban and rural settings. As part of this trial, roster schemes for participating volunteer responders have had to be developed for the two settings.

This paper will describe the roster scheme that has been developed using population statistics, demographic information, and spatial modelling techniques, for the urban region of 
North and West Belfast. The resulting roster model endeavours to minimize the response time of volunteers to SCA events, and thus ultimately improve SCA survival.

\section{The NI PAD study}

The NI PAD trial is set to monitor the effects of PAD in an urban and rural community throughout the trial year of 2005. The urban region of North and West Belfast spans a geographical area of $60 \mathrm{sq} \mathrm{km}$, with a population of 138591 (UK Census 2001 [17]), 52\% of which are male. The region is served by two ambulance stations which house paramedic-led ambulances, and a mobile coronary care unit (doctor-led). Based on recent trends, there is expected to be approximately 160 cases of SCA per year in North and West Belfast $[9,18]$.

The region is primarily urban residential, therefore the vast majority of SCAs will occur in residential accommodation, and on account of this, the majority of the AEDs deployed in this trial have been to AED-trained volunteers, who will carry the packs as they go about their daily business, with only a small portion of AEDs being placed at fixed public locations (such as shopping malls). Training of members of the Police Service of Northern Ireland (PSNI) and members of the public has been performed throughout 2004, and will continue to the end of 2005. It is expected that at least 300 volunteers will have been trained in the urban area, by the end of 2005.

All mobile volunteers (both members of the public and PSNI) are to be notified of possible SCA incidents by the Northern Ambulance Service (NIAS) through alphanumeric pagers. In the case of the PSNI, AED packs have been placed in patrol cars, and the Police Control Room receives the pages for all SCA events in the urban region, thus allowing the controller to alert the nearest available patrol car to attend. Members of the public who volunteer (hereafter referred to as lay volunteers) are expected to carry the AED packs, together with the alphanumeric pagers for a period of one week, at least once during the trial year.

In order to minimize the mobile volunteer's collective response time to SCA events, it has been necessary to develop a computer-based roster scheme for the lay volunteers.

\section{The model}

The roster for the lay volunteers has used the information collated at their training, as regards their home and work addresses (i.e. the potential point of origin of their response to any call), in order to assign them to different pager zones. This constraint, of having to assign volunteers to zones, is a result of the software used by NIAS (that automatically pages volunteers to SCA events). This software requires each pager to be assigned to a particular geographical zone (indicated by a central postcode, together with a radial distance), and since the total available manpower does not permit these zones to be changed weekly with the volunteers used, the zones of each individual pager must be predefined as a suitable region for all volunteers that will eventually utilize them.

The roster scheme has therefore had to consider what would be the most appropriate set of pager zones, given the overall aim to minimize the collective response of volunteers to SCA events. This has been done by taking into account factors such as the likely geographical distribution of SCA events; the number and disposition of volunteers; and the underlying road network. The method employed has assumed SCA events occur at the population-weighed centroid positions of the Census Operating Areas (COAs) in North and West Belfast. It also has assumed that volunteers start out at one of these centroid positions, determined by their home/work address. An outline of the steps involved in generating the roster is given below. 


\subsection{Modelling SCA events}

The number of SCA events occurring at any one particular COA was modelled by a Poisson process with the following parameters:

$$
\text { Number of SCA events in one year at COA } i \sim \operatorname{Poisson}\left(\lambda=\sum_{j, k} P_{j k} \times N_{i j k}\right),
$$

where $P_{j k}$ is the probability of SCA incidents in one year, for a given 5-year age group $j$ and sex $k$, and $N_{i j k}$ is the number of people in COA $i$ from the 5-year age group $j$ and sex $k$. The number of incidents recorded by the World Health Organization's MONICA project in Belfast [19], according to sex and age group over the period 1983-1993, were used to obtain $P_{j k}$, while population demographic information from the UK Census 2001 [17] for each COA, according to 5-year age groups and sex, was used to obtain $N_{i j k}$. The suitability of the model was assessed using a chi-square goodness-of-fit test, along with actual SCA incidents data collected for 2004 [9].

\subsection{Incorporating road network information}

Microsoft MapPoint Europe $2004^{\odot}$ was used to incorporate information on the road network. It was utilized along with Visual Basic code to obtain a matrix that holds the travel times between COA centroid positions. These times were calculated as the shortest travel times between the COA centroids (based on the actual road network), when travelling on the different categorized roads, at the speeds derived from the Northern Ireland Strategic Transport Model (NISTRM) [20]. These NISTRM derived speeds were considered to be reasonably low estimates to use in the first instance for two reasons. Firstly, this view is in agreement with the results of a comparison between NISTRM derived average speeds across the whole of NI and those derived from the Simplified Modelling of Spatial Systems (SMOSS) model [20], which was used in a recent review of ambulance services. Secondly, this conclusion was also drawn from the average speeds estimated from data, from a small pilot in 2004, in which 40 test pages were sent out to lay volunteers in the urban zone.

\subsection{Incorporating volunteer information}

The time matrix was then used to determine the choice of COA centroid positions that would be the "ideal" set of positions for volunteers to start at, in order to respond as quickly as possible, to as many calls as possible. This choice had however to take into account the actual number and disposition of volunteers, and so, COA centroid positions were eliminated as possible "ideal" starting positions when insufficient numbers of volunteers were within a reasonable travel time of them. For example, Figure 1 illustrates the positions of COA centroids in a part of North and West Belfast, by dots. The white dots indicate centroid positions of COAs that have at least 20 volunteers that can travel to them within 6 minutes, while the black dots indicate the other COAs in the region with insufficient volunteers to meet this requirement, (given the number and disposition of volunteers at the start of 2005).

\subsection{Maximizing the response to SCA through the choice of zones}

Having determined the number and distribution of SCA events in a given time period, the next component of the model looked at selecting the "ideal" starting points from the truncated set of COA centroid positions. This was achieved by aiming to maximize the 


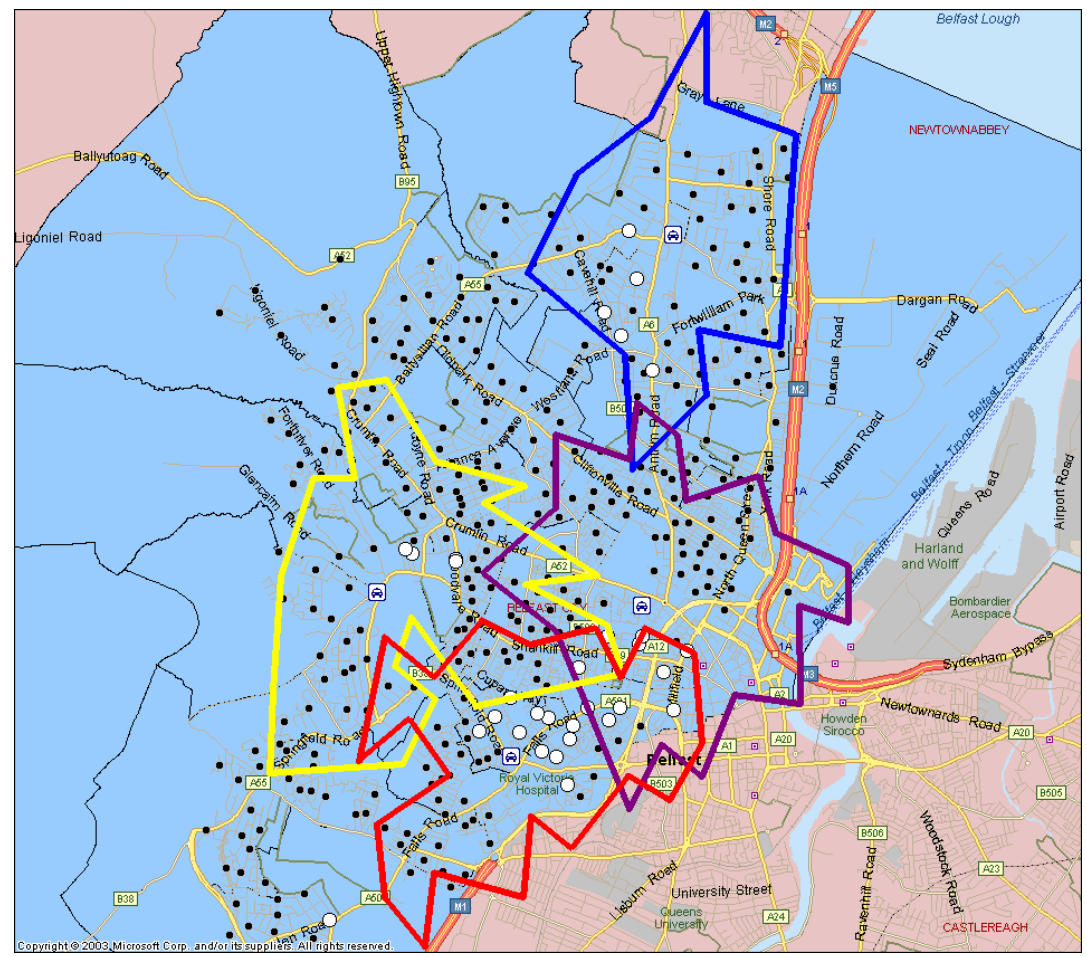

Figure 1. Illustration of how the zones were determined in the urban region

number of SCA events that could be attended within a given short travel time. The maximum covering location problem [21] was solved in Microsoft Excel $^{\odot}$ to obtain the optimal starting locations i.e.

\begin{tabular}{|c|c|c|}
\hline Maximize & $\sum_{k} h_{k} y_{k}$ & \\
\hline \multirow[t]{4}{*}{ Subject to: } & $y_{k}-\sum_{i} a_{k i} X_{i} \leq 0$ & $k=1, \ldots, N$ \\
\hline & $\sum_{i} X_{i} \leq M$ & \\
\hline & $X_{i}=0,1$ & $i=1, \ldots, N$ \\
\hline & $y_{k}=0,1$ & $k=1 \ldots, N$ \\
\hline
\end{tabular}

where

$$
\begin{aligned}
& h_{k}=\text { number of SCA events occurring at COA } k \\
& y_{k}=\left\{\begin{array}{l}
0 \text { if COA } k \text { cannot be reached within a given time period } \\
1 \text { if COA } k \text { can be reached within a given time period }
\end{array}\right. \\
& X_{i}=\left\{\begin{array}{l}
0 \text { if COA } i \text { is not the central location of a zone } \\
1 \text { if COA } i \text { is the central location of a zone }
\end{array}\right. \\
& a_{k i}=\left\{\begin{array}{l}
0 \text { if a zone with central location COA } i \text { does not cover COA } k \\
1 \text { if a zone with central location COA } i \text { does cover COA } k
\end{array}\right. \\
& M=\text { number of zones to be located } \\
& N=\text { number of COAs in the network. }
\end{aligned}
$$


Note that in performing this maximization, a number of the $X_{i}$ values were constrained to the value 0 throughout, since their positions had already been determined as undesirable.

Figure 1 illustrates the COA centroid positions chosen as optimal starting locations (indicated by car symbols), from the truncated set of COAs (the white dots). The 6-minute drive-time zones are also illustrated from each of these chosen locations, showing how far a person can drive from these starting locations, based on the underlying road network.

These drive-time zones were then finally utilized in deciding the size and position of each of the circular pager zones. The final postcode and radius chosen for each of the zones was set to cover the geographical area of the appropriate drive-time zone, together with any neighbouring areas of the city that had no/insufficient volunteers nearby.

\section{Results}

The seven overlapping zones used in North and West Belfast for the first 20 weeks of the trial are illustrated in Figure 2 by coloured rings. The coloured dots within the zones indicate the likely central position of each volunteer (i.e. their home/work area), coloured according to the zone in which they are meant to serve.

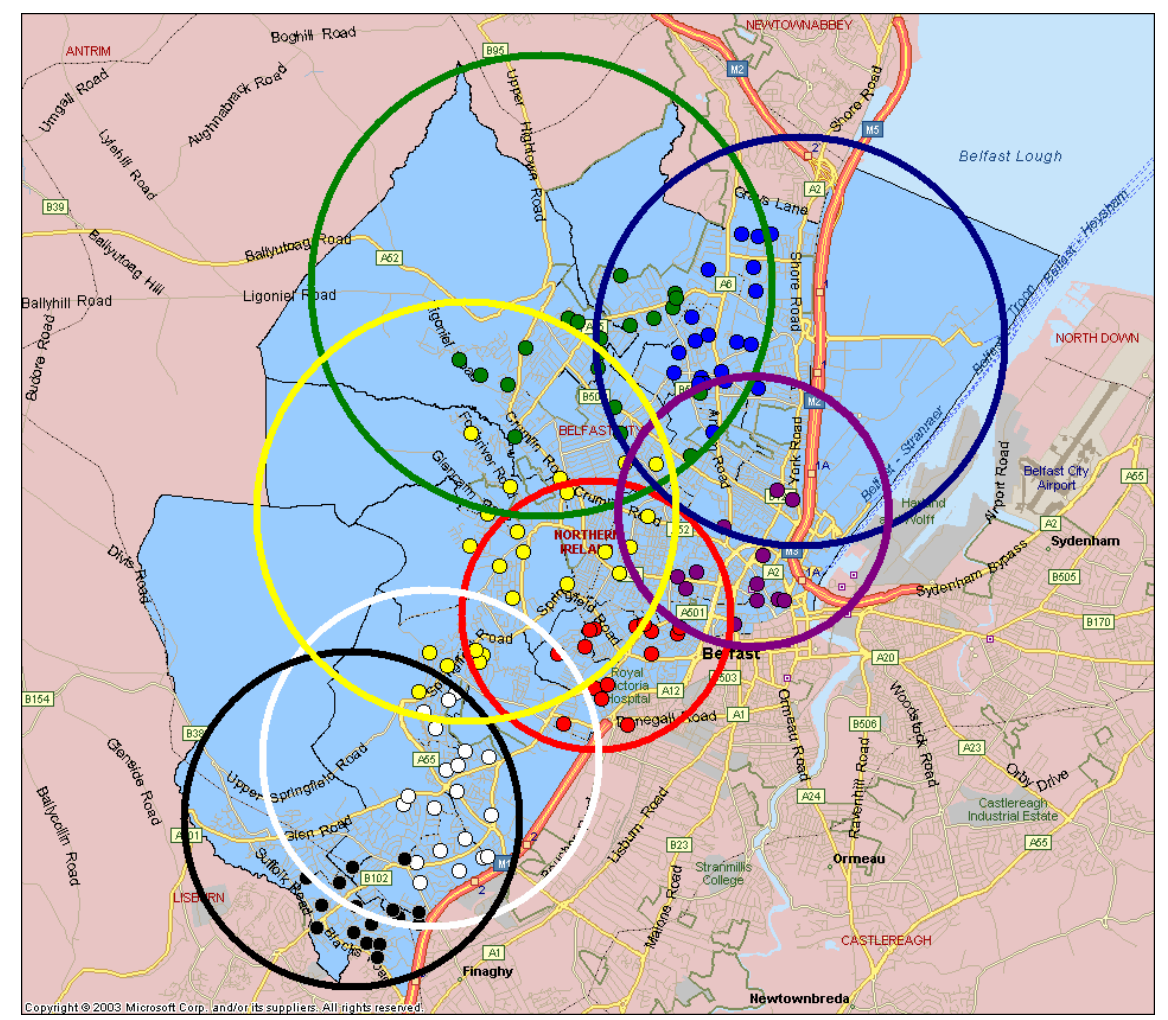

Figure 2. Geographical Zones (for the urban area)

\section{Conclusion and future work}

This paper has introduced a special computer-based roster scheme to allocate and manage volunteers working as part of a public access defibrillation trial. The model initially uses population statistics, demographics, geographical mapping software and spatial modelling techniques to subdivide the geographical location into appropriate paging zones (Figure 2). By estimating Sudden Cardiac Arrest occurrences using a Poisson 
process, the model, together with road network information, selects a roster which minimizes volunteer response time. Possible future work to that presented, is to incorporate the actual areas of the COA and other potentially influential variables such as congestion effects, and volunteer availability.

\section{Acknowledgements}

Special thanks must go to all the members of the PAD team, particularly Dr. M. Moore, for collecting all the volunteer and SCA data necessary for this work to proceed. Thanks to Evelyn Gardner for providing MONICA data.

\section{References}

[1] S. Yusuf, “The global problem of cardiovascular disease”, Int J Clin Pract Suppl, 1998, 94, pp. 3-6.

[2] C.S. Fox, J.C. Evans, M.G. Larson, et al, "Temporal trends in coronary heart disease mortality and sudden cardiac death from 1950 to 1999: the Framingham heart study", Circulation, 2004, 110, pp. 522-527.

[3] R.J. Myerburg, and A. Castellanos, "Cardiac arrest and sudden cardiac death", in E. Braunwald, D.P. Zipes, P. Libby eds., "Heart disease: a textbook of cardiovascular medicine", WB Saunders, Philadelphia, 2001.

[4] Z-J. Zheng, J.B. Croft, W.H. Giles, et al, "Sudden cardiac death in the United States, 1989 to 1998", Circulation, 2001, 104, pp. 2158-2163.

[5] R.O. Cummins, D.A. Chamberlain, N.S. Abramson, et al, "Recommended guidelines for uniform reporting of data from out-of-hospital cardiac arrest: the Utstein style", Ann Emerg Med, 1991, 20, pp. 861-874.

[6] J. Demirovic, and R.J. Myerburg, "Epidemiology of sudden cardiac death: an overview", Prog Cardiovasc Dis, 1994, 37, pp. 39-48.

[7] G. Nichol, I.G. Stiell, A. Laupacis, et al, "A cumulative meta-analysis of the effectiveness of defibrillatorcapable emergency medical services for victims of out-of-hospital cardiac arrest", Ann Emerg Med, 1999, 34, pp. 517-525.

[8] M.S. Eisenberg, B.T. Horwood, R.O. Cummins, et al, "Cardiac arrest and resuscitation: a tale of 29 cities", Ann Emerg Med, 1990, 19, pp. 179-186.

[9] M.J. Moore, B.M. Glover, C.J. McCann, et al, "Demographic and temporal trends in out-of-hospital sudden cardiac death in Belfast", Heart, (forthcoming).

[10] H.J.J. Wellens, A.P. Gorgels, and H. de Munter, "Cardiac arrest outside of a hospital: how can we improve results of resuscitation?", Circulation, 2003, 107, pp. 1948-1950.

[11] M.P. Larsen, M.S. Eisenberg, R.O. Cummins, et al, "Predicting survival from out-of-hospital cardiac arrest: a graphic model”, Ann Emerg Med, 1993, 22, pp. 1652-1658.

[12] The Public Access Defibrillation Trial Investigators, "Public-access defibrillation and survival after out-ofhospital cardiac arrest”, N Engl J Med, 2004, 351, pp. 637-646.

[13] T.D. Valenzuela, D.J Roe, G. Nichol, et al, "Outcomes of rapid defibrillation by security officers after cardiac arrest in casinos”, N Engl J Med, 2000, 343, pp. 1206-1209.

[14] R.L. Page, J.A. Joglar, R.C. Kowal, et al, "Use of automated external defibrillators by a US airline", N Engl J Med, 2000, 343, pp. 1210-1216.

[15] R.J. Myerburg, J. Fenster, M. Velez, et al, "Impact of community-wide police car deployment of automated external defibrillators on survival from out-of-hospital cardiac arrest", Circulation, 2002, 106, pp. 1058-1064.

[16] A. Capucci, D. Aschieri, M.F. Piepoli, et al, "Tripling survival from SCA via early defibrillation without traditional education in cardiopulmonary resuscitation”, Circulation, 2002, 106, pp. 1065-1070.

[17] http://www.nisra.gov.uk/census/Census2001Output/index.html.

[18] W.J. McIlwaine, M. Donnelly, M. Mallaghan, et al, "Deaths from ischaemic heart disease in Belfast", Brit Heart J, 1986, 55, pp. 330-335.

[19] H. Tunstall-Pedoe, K. Kuulasmaa, P. Amouyel, et al, "Myocardial infarction and coronary deaths in the World Health Organization MONICA Project. Registration procedures, event rates, and case-fatality rates in 38 populations from 21 countries in four continents", Circulation, 1994; 90, pp. 583-612.

[20] Department of Health, Social Services and Public Safety (NI), "Developing better services additional information - average travel speeds in Northern Ireland", 2003.

[21] M.S. Daskin, "A maximum expected covering location model: formulation, properties and heuristic solution", Transportation Science, 1983, 17, pp. 48-70. 